\title{
AUSENCIA DE DIOS \\ LO SAGRADO EN EL PENSAMIENTO Y LA POESÍA
}

\author{
POR \\ Gabriela Milone \\ Universidad Nacional de Córdoba (Argentina) - CONICET
}

\section{Pensamiento y poesía en la ausencia de Dios}

Nos proponemos leer en el presente artículo la experiencia poética y la experiencia de lo sagrado en el pensamiento filosófico contemporáneo, fundamentalmente desde filósofos modernos pos-nietzscheanos como Martin Heidegger (1889-1976), Georges Bataille(1897-1962), Maurice Blanchot(1907-2003), Emmanuel Levinas(1905-1995) y Jean-Luc Marion (1946). Gracias a este recorrido, podremos decir que lo desconocido, la otredad, la pasividad, la inmediatez y la imposibilidad son rasgos fundamentales de la noción de experiencia; y que articulando esta noción con la poesía, el pensamiento y lo sagrado, nos permite a su vez leer producciones poéticas contemporáneas en Argentina, como la de Héctor Viel Temperley (Buenos Aires, 1933-1987), Hugo Padeletti (Santa Fe, 1928), Oscar del Barco (Córdoba, 1928) y Hugo Mujica (Buenos Aires, 1942).

Es así como relacionando experiencia con lo sagrado en el pensamiento contemporáneo, nos es posible pensar en un tipo de experiencia que se vincula con la filosofía y se manifiesta en la escritura poética, específicamente en lo que pensamos como experiencia de la ausencia, vaciamiento o falta de lo sagrado. Ésta se da en el marco de la crítica a los discursos teológicos que prescriben un "contenido" para la experiencia religiosa; $y$ es por ello que lo que acontece es precisamente una experiencia de lo sagrado que se hace por fuera de los dogmas y las religiones, asumiendo la muerte del Dios ontoteológico de Occidente, su vaciamiento y su falta (Milone 22).

Sin embargo, ¿qué podría configurarse como "Dios" si "Dios ha muerto"?; o bien, ¿puede acontecer algo que se experimente y se nombre como "Dios"?; y por último ¿es posible una experiencia religiosa de la ausencia y del vaciamiento de lo sagrado? Afirma Blanchot: "Dios ha muerto: Dios significa Dios, pero también todo aquello que, por un movimiento rápido, intentó ocupar su sitio, es decir, el ideal, la conciencia, la razón" (244). Este espacio de lo sagrado es lo que queda vacante con la muerte de Dios en Occidente. No hay representaciones ni conceptos que puedan sostenerse frente a ese vacio imposible que resulta ser lo sagrado cuando Dios ha muerto. Frente 
a esta ruptura, el lenguaje se hace impersonal, anónimo, neutro; y como portador de la imposibilidad de decir eso fundamental que se experimenta, es el lenguaje mismo -en su afuera (Blanchot, Diálogo inconcluso; Foucault) y en su cercanía con el lenguaje poético- lo que adviene como sagrado.

Al vincular el pensamiento, lo sagrado y lo poético, nuestra lectura asume la importancia y necesidad de pensar estos cruces y de (re)establecer un diálogo entre todas las experiencias (del pensamiento, religiosa y poética), en la misma senda ya mencionada del diagnóstico de la muerte de Dios, esto es, de la ausencia y del vaciamiento de lo sagrado. Es así como entra la crítica de Heidegger a la ontoteología, junto a aquello que Levinas piensa en relación a los discursos tematizadores de lo divino. Por su parte, también interesa la ruptura que realiza Bataille con los sistemas doctrinales que reglan y servilizan lo sagrado y regulan la experiencia religiosa; como así también lo que Marion expone en relación a la idolatría conceptual que busca acercar lo divino y así lo anula en cuanto tal. En todos estos pensadores podemos observar una problematización de lo sagrado en el seno del pensamiento y del discurso de la ontoteología, cuestión que nos conduce a la necesidad de dar cuenta no sólo de la experiencia de lo sagrado, sino también y fundamentalmente de la relación que ésta mantiene con una experiencia radical del lenguaje, esto es, una experiencia del afuera de las significaciones, de límite o umbral de lo decible en el murmullo del lenguaje. Experiencia fuera de la lógica y de las convenciones, que implica una crítica explícita al lenguaje racional y conceptual y que, por ello mismo, se manifiesta íntimamente vinculada a la poesía, vale decir, a la experiencia poética como experiencia sagrada del lenguaje en tanto afuera de los significados arbitrarios de las palabras. Es así como podemos señalar que experiencia de lo sagrado y experiencia poética están unidas (e incluso quedan asimiladas en algunos casos), en esta línea filosófica que piensa lo sagrado en términos de pasaje (Heidegger), de absolutamente otro y de hay (Levinas), de desconocido, imposibilidad y neutro (Blanchot), de desnudez y no-saber (Bataille), de distancia y anonimato (Marion).

En el hay la poesía se hace eco del pensamiento y, en el murmullo de un lenguaje que balbucea en el afuera de los nombres, pronuncia un dios con minúsculas (Mujica), un Dios en el cuerpo (Viel Temperley), un vacío sagrado (Padeletti), un dios-sin-dios (del Barco).

Es el lenguaje de la poesía el que acontece en el lugar donde el pensamiento sólo puede moverse dando rodeos. Pero es el pensamiento el que advierte las sendas (perdidas) que la poesía sigue para dar cuenta de esa experiencia de apertura, afuera e inmediatez frente a la cual la poesía acaso no pueda nombrar, aunque sí responder. No obstante ¿cómo es que la poesía responde?, e incluso ¿mediante qué recursos, vías o rodeos? Nuevamente, en los pensadores hallamos las claves para leer a los poetas: por un lado, el "hacer señas" de Heidegger, ese lenguaje que no dice sino sólo que

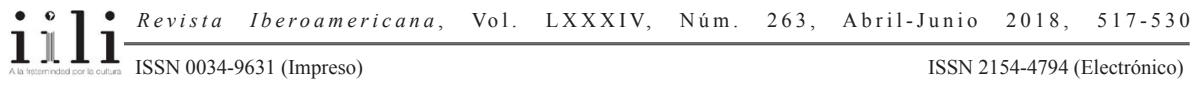


indica, y da cuenta de su imposibilidad mostrando tan sólo el pasar de lo sagrado; la concepción de la poesía para Bataille, la cual implica ese sacrificio de los significados convencionales en función de liberar la fuerza poética de las palabras; por último, el modelo discursivo de desposeimiento de sentido de Marion que se desvía de la lógica asertiva occidental y encuentra una vía para responder a lo imposible.

De este modo, en la confluencia de pensadores y poetas se configura un pensamiento poético, vale decir, un pensamiento que paradójicamente se sabe en el umbral tanto del pensamiento cuanto del lenguaje, y que por esta misma razón convoca ese riesgo propio de la experiencia, esa ruptura y desgarradura por la que Bataille, por ejemplo (pero antes, Heidegger, abriendo el camino de las sendas perdidas) proponía un tipo de comunicación extraña y extranjera al discurso como lo es la poesía. Justamente transitando los recorridos teóricos de Bataille y de Blanchot es que podemos abordar a la poesía no sólo como acto literario, estético, sino también como una experiencia cercana al pensamiento; y esto en función de postularla principalmente en términos de una experiencia de algo más en relación al lenguaje, algo infinitamente otro en su exceso de sentido, experiencia de una radical abstención de poder (del yo), de abandono y de afuera de la relación sujeto/objeto.

Desde un poeta como Rene Char, por ejemplo, Blanchot piensa que la poesía es el habla con lo desconocido, la energía que disloca la realidad discursiva, que anula la voz propia del yo para pluralizarse en la otredad que experimenta y convoca. Así, la relación del poema con el pensamiento es una relación que, al menos para Blanchot, no buscaría decodificar o sobreimponer categorías del pensamiento lógico a ese pensamiento del afuera donde adviene el poema. Un pensamiento en consonancia con la poesía implica una discursividad que se libera del "discurso", ya que en su propia imposibilidad, encuentra el terreno para su manifestación en una dimensión donde se suspenden las coordenadas que rigen al lenguaje conceptual. Blanchot incluso habla de una superficie que paradójicamente es también una profundidad, vale decir: el afuera donde se habla lo imposible, eso que late en el fondo de las cosas (Bataille), en lo improbable que sin embargo es todo lo que es (Bonnefoy), vale decir, la presencia sagrada de la inmediatez (Blanchot).

Se trata precisamente de pensar la poesía como una operación soberana de lenguaje, según Bataille, operación que implica violencia no como acción sino como intensidad, esto es, como el sacrificio del sentido de las palabras en búsqueda de la liberación de lo sagrado en y del lenguaje. Se trata pues, insistimos, en esa experiencia de pensamiento y de poesía que genera una relación-sin-relación con lo desconocido y lo neutro, esto es, un vínculo sin términos definitivos ni determinados, sin la relación sujeto-objeto. Es el otro, lo otro, esto-lo-desconocido, como dice Blanchot, lo que adviene en la experiencia del pensamiento y de la poesía frente al vaciamiento de lo sagrado, experiencia que abre el afuera (de las representaciones y significaciones)

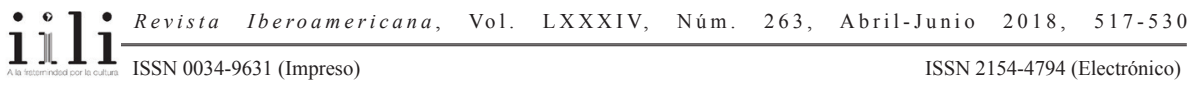


imposible de pensar, esto es, sin posibilidad ni poder, en el abandono, la distancia, la desnudez, la intemperie, la falta.

Sin objetos para un sujeto, la relación-sin-relación que la poesía establece (de no-conocimiento, o de no-saber) es absolutamente otra, una relación que no puede afirmar ni negar, sino sólo responder con las palabras que de antemano se sabe no podrán enfrentarse a lo ilimitado, más que en su desastre, en su noche de significado, en el sacrificio de su sentido, en el movimiento de su contradicción y de su repetición. Así, el poema se hace él mismo desgarradura en lo neutro, en lo que habla sin el signo positivo o negativo, o sea, sin referir a significados estipulados en paradigmas de sentido. En el umbral de todo sistema, acontece en el poema esa experiencia del responder sin preguntar, o antes bien y en términos de Blanchot, del responder a lo imposible (que es lo sagrado en el vaciamiento de sí mismo, en su ausencia y su falta) mediante un decir que es acción de la inacción, pasión e intensidad de la poesía en la pasividad del lenguaje. Responder a lo imposible implica asumir ese más que hay en lo decible, pero que al hacerlo no pretende nombrarlo sino que abre una zona de dejación donde lo ajeno resta como ajeno y donde lo desconocido ad-viene como desconocido.

Esa excedencia, exterioridad de lo pensable y cognoscible, es lo que la experiencia poética muestra como su núcleo ante la constatación de que hay algo en el mundo y que ese algo es lo desconocido para el pensamiento y lo imposible para el lenguaje. Y sin embargo, es lo que compele a la voz poética a dejarse, a abandonarse en la fisura de las representaciones, en la que se abre el esplendor del hay, que irrumpe en el mundo y que exige el riesgo de la pasividad y la serenidad; ese riesgo o peligro propio de la experiencia que supone perderse, como diría Bataille, en la noche del no-saber, o como afirmaría Blanchot, en la pasión pasiva de lo neutro.

Experiencia de lo sagrado en lo neutro, experiencia de lo poético en el afuera del lenguaje: así confluyen en estas páginas pensamiento y poesía. La poesía y lo sagrado se relacionan íntimamente no porque una esté al servicio del otro, sino porque ambos se filian a una experiencia de pensamiento y de lenguaje dada en esa retirada del esplendor divino como dice Nancy, esto es: en la imposibilidad (de la experiencia), en el afuera (del lenguaje), en lo neutro (del pensamiento), en el vaciamiento (de lo sagrado) (Lieux divins).

En la muerte de Dios que diagnostican y recorren los filósofos como pasaje, borradura, otredad, hay, distancia e inmediatez, los poetas despliegan sus experiencias poéticas en el peligro de lo que adviene, el riesgo de lo desconocido, la indeterminación de lo que acontece, la excedencia de lo decible, en suma: en la experiencia imposible de un lenguaje y un pensamiento otro que responde desde ese espacio de lo sagrado, espacio vaciado y paradojal donde lo sagrado es su falta, o mejor, donde hay una falta que es en sí misma sagrada. Pensadores y poetas han sido convocados en estas páginas con el mismo fin de recorrer la experiencia extrema y arriesgada de lo que queda de lo sagrado, cuando en el poema esplende su vaciamiento, su falta, su distancia incalculable. 
No obstante, ¿qué se entiende por "vaciamiento de lo sagrado"? Comprender esta noción implica repensar la "muerte de Dios" como el proceso de vaciamiento de los conceptos y los valores estipulados para lo sagrado dentro de la tradición de la ontoteología, tradición discutida tanto por Heidegger como Levinas, Blanchot, Bataille y Marion. Y aún más, pensar ese vaciamiento de lo sagrado específicamente como problema de pensamiento y de lenguaje poéticos y no como una cuestión teo-teológicapolítica ligada al denominado retorno de lo religioso. Así es como "el pensamiento del afuera" (Foucault 298) encuentra en este diagrama una particular resonancia, en tanto se trata de un pensamiento sobre una experiencia de lenguaje que, en primera instancia, no se filia a lo "místico" (o sea, como experiencia que se pierde para reencontrarse en un significado último), sino que se trata del "lenguaje abierto sobre su propia ausencia" (Foucault 300). En este sentido, y siguiendo a Nancy, pensar el vaciamiento de lo sagrado es arriesgarse a postularlo como suspensión de las categorías y significados asignados dentro de la configuración de la ontoteología.

Nancy habla de "ausenteísmo" como ese horizonte de retiro, de ausencia de toda presencia sagrada que garantiza el contenido ontoteológico, como ese espacio de lo sagrado que queda vacante con la muerte de Dios en Occidente (en consonancia con la "ateología" de Bataille). No habría representaciones ni conceptos que ejerzan su poder de denominar ese vacio imposible en donde el lenguaje se hace impersonal, anónimo, neutro: es el lenguaje mismo -en su cercanía con el lenguaje poético- lo que adviene como sagrado.

De este modo, reconocemos como "experiencias poético-religiosas" a aquellas que se dan en esferas propias del pensamiento filosófico y del lenguaje poético, y que se caracterizan por la imposibilidad y la inmediatez frente a lo que se experimenta como vaciamiento de lo sagrado, y que no puede ser conocido ni abordado por medio del pensamiento y del lenguaje conceptual. De este modo, los rasgos sobresalientes o los modos de la categoría de la experiencia del vaciamiento de lo sagrado son: ausencia, afuera, desnudez, imposibilidad, inmediatez, hay. No habría pues ni una negación de lo sagrado ni una filiación directa a una religión en particular. No hay a-teísmo sino a-teología: lo sagrado se da en la falta que queda con el vaciamiento del concepto de Dios. De esta experiencia dan cuenta, según nuestro recorrido, tanto la santidad de la ausencia de Mujica, cuanto la horizontalidad de un éxtasis internado en el cuerpo de Viel Temperley, la atención a lo inviolado de la inmediatez de Padeletti y el eso sin nombres que acontece en la intemperie del hay de del Barco.

\section{EXPERIENCIAS POÉTICO-RELIGIOSAS EN LA POESÍA ARGENTINA CONTEMPORÁNEA}

La experiencia poética de lo sagrado en la escritura de Hugo Mujica se da en relación a lo que observamos como una experiencia de la ausencia de Dios, de lo sagrado sin Dios que se caracteriza por el acontecimiento de un dios por fuera de los

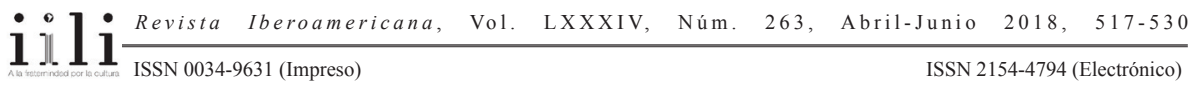


conceptos, y como experiencia del lenguaje abierto en la distancia y el vaciamiento de lo sagrado. Por fuera de las codificaciones y determinaciones de un Dios teológico, la experiencia aquí es la del testigo del vaciamiento de lo divino, de la borradura hasta la ausencia del Dios codificado de las religiones; experiencia que reconoce como lo sagrado a la ausencia misma de lo sagrado, esa "falta" de la que hablaba Heidegger. Y es esa ausencia sagrada la que expone y recorre esta experiencia poética, ausencia que no parece manifestarse al modo de la Nada de los místicos tradicionales del cristianismo con la cual se buscaba un contacto directo en el éxtasis al que se accede mediante un trabajo de ascesis, un "ascenso" escalonado a la unión del alma con Dios. Decimos que esta experiencia de lo sagrado no es mística, y lo hacemos en relación con Blanchot, vale decir, como una experiencia imposible de lo inmediato, en un modo otro que, antes que buscar el contacto directo, reserva una "ausencia infinita" (Blanchot 80), sin términos ni relación, una espera sin término, diferente a la que surge de la práctica y fe del creyente. Esa "falta", que acontece como inmediatez e imposibilidad, es lo que resta como experiencia de lo sagrado luego de la "muerte de Dios", y es por esta razón que no hay contacto posible, sino experiencia de la borradura misma de Dios. Y sin embargo, es posible aquí, en este vacío, sostener una experiencia poética que asume su imposibilidad, que es testigo de la borradura y que responde por esa ausencia. Desde aquí, hay que tener en cuenta una preocupación que Blanchot declara: ante la conciencia del vacío que tomamos después de la muerte de Dios, debemos cuidarnos de que ese vacío no vuelva a adquirir los mismos atributos, funciones y valores del Dios eliminado; no haciendo un intercambio de nombres ("vacío" por "Dios"), sino un cambio de pensamiento cercano a lo que postulaba Heidegger con "el último dios"; pensamiento que se enfrente con su vacío. Porque en consonancia con Levinas, en la experiencia poético-religiosa de Mujica se trata de abrir un espacio para un dios diferente al conocido, representado, tematizado.

Hay una noción que está en Mujica (y que reaparece, aunque con matices, en del Barco) que es el "dios sin dios", desde la cual postulamos esta experiencia de lo sagrado como un vaciamiento de Dios en términos de "paraíso vacío" donde lo único que acontece es la ausencia, donde "dios" se escribe con minúsculas y se experimenta en la distancia insalvable e infinita de su borradura, un dios totalmente otro que se muestra sólo como huella. Este pasar, que contempla la ambivalencia y la paradoja, está presente explícitamente en varias ocasiones a lo largo de la poesía de Mujica. Por caso, en el primer libro, Brasa blanca (1983), un poema dice: "lo que muere al pasar es lo que pasa" (Poesía completa 31). Luego, en el poema "Otra vez otro invierno" de Para albergar una ausencia (1995), enuncia:

lo imposible

lo que pasará sin pasarnos

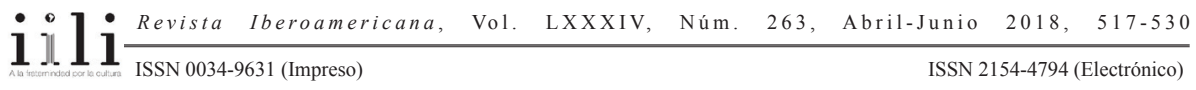


lo que no llegando nos pone a salvo de volver la mirada. (Poesía completa 313)

La otra mención la hallamos en "Reflejo", de Casi en silencio (2004), donde se afirma: "hay que mirar pasar/el agua/ hasta ver tan sólo/ el paso del agua/ hasta ver en su transparencia/ el reflejo de la propia ausencia" (Poesía completa 450). Y finalmente, encontramos otra alusión en el poema "Encrucijada" de Sed adentro (2001): "paso a paso se borra el camino y/ dibuja allí, en lo borrado, / la ausencia que busco" (Poesía completa 348). De este modo, el poema se hace en el espacio de radical confrontación entre la obligación de responder ante la falta de lo divino y lo imposible de nombrar en esa ausencia, en la existencia extrema que el poeta acoge a costa de no poder decir, en esa espera absolutamente despojada a la intemperie.

Donde sí hallamos una experiencia cercana a la mística, aunque con rasgos singulares, es en la escritura de Héctor Viel Temperley. Aquí lo que acontece es un tipo particular de éxtasis en la apertura hacia una mística otra. Cabe aclarar que la originalidad de esta escritura poética no habilita una interpretación directa desde un conjunto de creencias religiosas, sino que, antes bien, evidencia la plenitud de un estado de comunión en apertura y éxtasis que acontece por fuera de determinadas doctrinas y convenciones religiosas. De este modo, centrando nuestra lectura específicamente en el libro Hospital Británico (1986), puede observarse la manifestación de una experiencia mistica invertida, completamente diferente a la tradicional. Afirmamos esto dado que allí acontece la experiencia de una mística que con Bataille podría denominarse "teopática", en donde lo sagrado no puede ser pensado desde la unión mística del Alma con Dios, sino en el éxtasis del cuerpo que experimenta la sobreabundancia de lo sagrado en la desnudez y el vaciamiento de contenidos y dogmas religiosos. Que en Viel Temperley no haya a-teísmo sino a-teología da cuenta de que no se trata de una negación de lo sagrado; antes bien, se evidencia un corrimiento o inversión de los contenidos atribuidos a un "Dios" (definido desde sistemas dogmáticos) para hacer de lo sagrado una experiencia de desnudez, plenitud y éxtasis del cuerpo. Observamos que el invertir la mística tradicional no abandona ni niega la experiencia de lo sagrado, porque no vemos en esta poética simplemente una negación del Dios onto-teológico ni únicamente la manifestación de una mística excéntrica. Si bien hay una innegable dimensión de religiosidad cristiana en la poética de Viel Temperley, vemos que esta religiosidad se evidencia en una compleja vivencia de lo sagrado en el cuerpo que siempre es nombrado como "Dios", pero cuyos rasgos dan cuenta de un alejamiento de las conceptualizaciones onto-teológicas de lo divino. Observamos en esta poética una cantidad de matices desde los cuales postulamos esa inversión respecto de la mística tradicional, fundamentalmente en relación a una experiencia de lo sagrado que es vivida como carne que rodea, siendo así una divinidad material experimentada en el cuerpo.

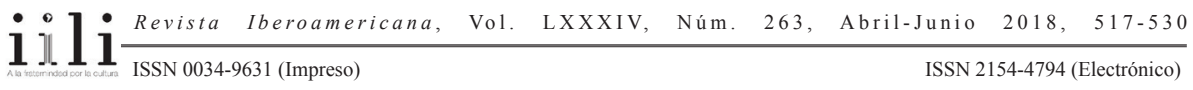


Esta complejidad de interpretar una experiencia religiosa que a su vez acontece como una mística ateológica, es lo que nos lleva a un tratamiento de la misma que procede mediante matices para dimensionar sus rasgos particulares. Es así como podemos ver que aunque esta experiencia no evidencie usos de conceptualizaciones onto-teológicas de lo divino sí manifiesta la presencia de representaciones y figuras como la de Cristo (y específicamente la de Christus Pantokrator en Hospital Británico), o la denominación de "Señor" en algunos pasajes; incluso, cabe destacar la importancia de la presencia de la plegaria y la oración en esta poesía. Vale decir que la crítica a la onto-teología que puede observarse funcionando en esta poética no implica una pérdida de la fe ni la adopción de una postura ya sea absolutamente idolátrica o totalmente iconoclasta. Antes bien, lo que forma parte tradicionalmente de la poesía mística, en Viel Temperley se sub-vierte y sigue siéndolo aunque con signo material, en tanto no hay abandono del cuerpo (como tampoco hay olvido del alma), ni contemplación en términos de unión nupcial con Dios, sino comunión como golpe brusco e intenso de lo sagrado que se experimenta. Los rasgos son de brusquedad e intensidad, de unión delicada o trato de amor, para decirlo con palabras de Santa Teresa de Ávila; rasgos que específicamente pueden verse en las figuras e imágenes del "ancla", la "velocidad" y el "hambre" en Hospital Británico. En relación con esto, podemos ver la horizontalidad (y no la verticalidad) de esta experiencia mística dada en el movimiento de la internación en el éxtasis, del cuerpo tendido en la cama del hospital por la enfermedad. La enfermedad, a su vez, significa un elemento clave a considerar, ya que evidencia una vinculación directa con el éxtasis y la afirmación del cuerpo en el hospital realizada por el poeta, cuestión que resuena especialmente de manera inversa respecto al camino de ascensión del alma hacia Dios de los místicos tradicionales (movimiento vertical que niega el cuerpo para ser todo alma). Estos matices nos permiten así conocer cómo esta poética hace uso de imágenes y expresiones alejadas de las figuras y símbolos tradicionales de místicos como San Juan de la Cruz. Sin embargo, este alejamiento da cuenta de un giro particular que, reiteramos, produce una inversión y configura la escritura poética de una mística particular, otra, corrida de los tópicos místicos tradicionales. La mística ateológica y teopática de Hospital Británico no dice "alma" en lugar de "cuerpo", y sin embargo, sigue diciendo "Dios" cuando da cuenta de lo sagrado experimentado, un "Dios" que (más cercano al "dios" con minúsculas de Mujica) no es tematizado ni conceptualizado en un discurso teológico, sino que es experimentado como límite de lo posible en el extremo del no-saber.

Así, podemos observar que la inversión de la mística tradicional se da en que "Dios" no es el epílogo de un camino de salvación, sino la experiencia de un éxtasis que acaece en lo repentino de un golpe, en la internación en lo desconocido, en el estallido de las esquirlas, en la perdición de sí mismo por la experiencia de lo sagrado. Porque la experiencia poético-religiosa que despliega el Hospital Británico es la de

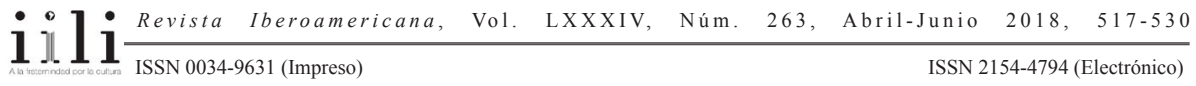


un Dios que se experimenta en el éxtasis de un cuerpo recluido/abierto en la desnudez insoportable de una comunión extática.

Quien sostiene una similar experiencia mística pero con signo completamente diferente es Hugo Padeletti, en cuya poesía puede leerse desde aquello que el mismo poeta denomina como "experiencia estético-mística de la atención" (262). Este tipo de experiencia se daría en el vaciamiento de conceptos de la mente, en la serenidad frente a los objetos, en la mansedumbre de la palabra, en la celebración de lo poco, en la experiencia de inagotabilidad de lo simple, en el sos-tenimiento de la mirada en el ahora de lo que acontece. Ciertamente, en Padeletti se vislumbra una experiencia de lo sagrado exenta de contenidos religiosos y/o dogmáticos, vale decir, de aquella experiencia espiritual que, según afirma el mismo poeta, comparten todas las religiones aunque no pertenezca a ninguna. Cada poema se halla en sintonía con la celebración de la simplicidad, con la contemplación tranquila de los objetos en su estar, con la apertura de los sentidos para la captación de lo que se revela en su simpleza y en su inagotabilidad. La experiencia se nutre del acto de despojar la mente de conceptos, en el reconocimiento de la pérdida de lo simple por lo conceptual. En este sentido, por caso, en el poema titulado "Uttar Pradesh" de Padeletti resulta emblemática la tensión entre la experiencia, por un lado, y el conocimiento conceptual y discursivo, por el otro. Aquí, el conflicto se presenta entre la reducción que se opera en las clasificaciones conceptuales y la consiguiente pérdida de lo simple en lo singular de cada cosa, de cada sabor:

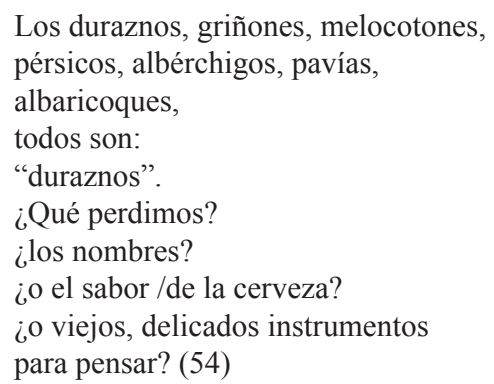

Podemos vislumbrar en este fragmento del poema cómo lo simple puede ser reencontrado en cada cosa, en cada fruta sabida (conocida y gustada) en su carne única, en su sabor particular, en su nombre propio. El poeta habla de su singularidad perdida, de su ser único que ha sido borrado por las generalizaciones de las clasificaciones. Lo que el poema evidencia es la manera en que la experiencia se amplía al despojarse la mente de conceptos para así enfrentarse a lo inagotable del mundo, a las particularidades ocultas por las conceptualizaciones, a lo perdido por esos "instrumentos de pensamiento" que

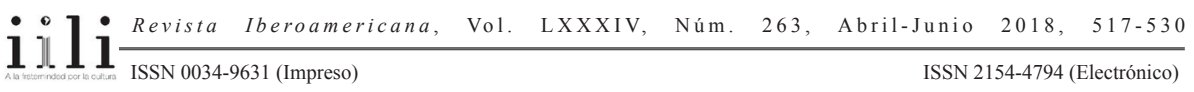


no logran nombrar a cada cosa en su unicidad. Lo que parece evidenciarse en los poemas de Padeletti es una mansedumbre del pensamiento y la palabra, un no-desbordamiento del lenguaje en el dejar-ser a las cosas del mundo, percibirlas en su manifestación plena y única. En este mundo poético, todo está con-centrado en la atención paciente del poeta, todo lo que rodea espera ser captado en su verdad y simpleza, aunque no conquistado como objeto, como útil. La atención es esto, dice la voz poética, "este ahora", una suficiencia, una completud de intensidad que se deja a su propio afuera extático. Ese ahora es el que acontece, no hay una acción del sujeto para que acontezca, sino que adviene; el yo pasivamente dejado a su apertura, activamente luego escribe el poema, en el asumir la experiencia de lo que no pasa mientras todo pasa. La experiencia es de contemplación y no de meditación, y es el mismo Padeletti el que ha insistido en la diferencia que existe entre ambas experiencias, en la medida en que la segunda, la meditación, es esencialmente discursiva (al estilo de los ejercicios espirituales de, por caso, Ignacio de Loyola), mientras que la contemplación es la experiencia de la "atención pura", del aquí y ahora fundamental, de la mente y la mirada concentradas, paciente y pasivamente, receptivas de lo que acontece en su silencio. En este sentido, Padeletti habla de "experiencias espirituales" (135), donde la mente vaciada de contenidos conceptuales se entrega a la contemplación de lo real, sin atributos, sin determinaciones, sin nombres, "sin residuos" dirá el poeta. Aquello que el poeta nombró como "milagro de la simplicidad original" (143) es lo que condensa esta experiencia estética de lo sagrado no confesional, no convencional, no conceptual. No hay dios aquí, ni como ídolo ni como ausencia; pero sí hay una experiencia innegable de lo sagrado que se abre en el fondo de las determinaciones y que se hace en el acontecimiento de la inmediatez que brota del hay ya sin conceptos ni objetos, donde lo que el discurso conceptual pierde es recuperado por la palabra poética, por la atención puesta en el vacío donde acontece la vibración de lo inmediato.

Por último, convocamos la escritura de Oscar del Barco, en la cual acontece la disolución del yo y del lenguaje; cuestión que nos permite vislumbrar que la poesía para este autor se vincula con la experiencia de lo sagrado en la medida en que acontece en la excedencia del pensamiento y del lenguaje poético, en la ruptura que hace de lo sagrado una experiencia de vaciamiento y afuera. De este modo, en esta poética se evidencia una experiencia de la intemperie sin fin (términos que del Barco toma del poeta argentino Juan Laurentino Ortiz), vale decir, en ese afuera del pensamiento y en esa inmediatez de lo que se experimenta como exceso: se trata de la exterioridad a la que el poeta se ve arrojado, de la impersonalidad del habla, de la distancia de lo divino dada en la desnudez del lenguaje conceptual. La escritura poética de Barco está íntimamente ligada a su trabajo filosófico, dado que en su labor poética se evidencia una puesta en práctica de los puntos centrales de sus reflexiones teóricas, esto es: el poema como manifestación y acontecimiento, el desplazamiento de la idea de poeta

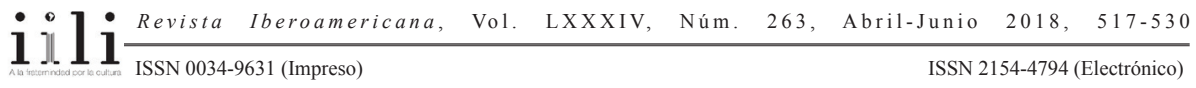


o autor por el espacio abierto del poema, la experiencia de la intemperie a la que se expone quien escribe, el exceso del lenguaje que subyace en el fondo de los nombres dados a las cosas.

Indudablemente, aquello que del Barco denominó como la fascinación del lenguaje en su libro La intemperie sin fin (2008), se constituye como el leitmotiv de su obra, tanto filosófica como poética. Ya sea que el pensador ensaye sobre filósofos (Hegel, Nietzsche, Heidegger, Wittgenstein, Bataille, Blanchot, Levinas, entre otros), o sobre poetas (principalmente, J.L Ortiz, pero también, y no con menos importancia, los románticos alemanes y Mallarmé); e incluso cuando es el poeta Barco el que traza las huellas del habla en la manifestación de un poema, esta "fascinación del lenguaje" no desaparece. Esta atracción que el lenguaje ejerce, sin embargo, no es ejercida por alguien; se abandona todo lo que constituye el campo de lo subjetivo en pos de avizorar un plano, o mejor, una red de caminos que parten de la razón pero para extremarla, para llevarla a su límite, esto es, a su menos, a su mínimo de acción, a una suerte de no saber (en términos de Bataille, esto es, un saber que no es conocimiento sino éxtasis, un afuera de las categorías racionales). El empuje lo realiza el lenguaje hacia sí mismo, para dejar de ser lenguaje (o sea, dejar de ser "ser" y "lenguaje", o lo que es lo mismo, dejar de ser mundo representado por los nombres del logos). Salir del lenguaje implica dejar de poseer el mundo, dejarse en la más radical intemperie de lo sin nombre, desposeerse de las mediaciones de los signos que atraviesan lo que es y desmembrarse en el afuera de lo conocido, en el allí que habla de lo que hay, de la abertura imposible de lo indeterminado. Así, en la obra de Barco hay una dimensión poética ligada a lo sagrado que surge en esa ruptura del yo y del lenguaje, en una intimidad abierta que encuentra en la poesía la zona propicia para su acontecimiento. Como el autor sugiere en Exceso y donación: La búsqueda del dios sin dios (2003), Dios es un referente vacío, es el nombre que tradicionalmente se le ha dado a la pura excedencia del lenguaje, a eso ilimitado a lo que las palabras se dirigen pero a lo que no pueden más que rodearlo. Dios es (aunque, estrictamente, no sea nada, esto es, nada posible de ser nombrado como Ser) lo abierto del mundo y de las significaciones, el fuera de las palabras, el puro pronombre sin referencia, más que su continua donación. Porque está fuera de las posibilidades del nombrar, decimos "Dios" a eso que experimentamos como exceso, gratuidad, gracia.

Así, el poeta -que no existe como tal, sino como una intemperie del lenguaje en donde hace eco la gracia donada del lenguaje-se enfrenta a la vacuidad del nombre de Dios y de este modo la poesía mantiene un continuo estado de comunión con la " [ ... ] excedencia incandescente que supera todo lo dado empíricamente como objeto y como sujeto" (del Barco 13). A la espera de la excedencia innombrable, de esa gracia, el poeta, en el vacío inconmensurable de nombres imposibles se abandona, haciéndose fondo del habla del mundo y se entrega al "calmo advenir de lo que llamamos otro" (Barco 7).

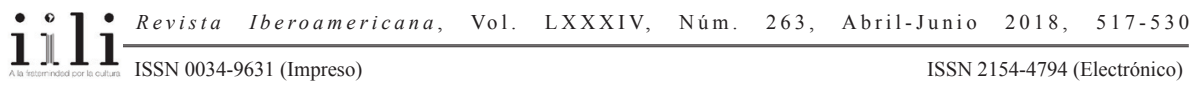


Lo que se es, lo abandonado por el abandono y en el abandono de las palabras (esto es: por la gracia acaecida en la apertura de la excedencia de lo que es, en ese plus imposible de decir y que sin embargo se manifiesta, como una epifanía, en los intersticios de los conceptos; y en el habla que se abre entre el silencio y la palabra (como en un estado intermedio), se trata de una "[...] espera sin contenido [...] que no espera nada [...] inconmovible, total" (Barco 15). La espera hace del hombre, en el abandono de su yo, una apertura a la excedencia, a eso siempre más que arrasa como un más-allá imposible de decir: aquí se cifra la experiencia de lo sagrado en esta escritura poética.

\section{CONSIDERACIONES FINALES}

Podemos concluir diciendo que relacionar la categoría de experiencia con lo sagrado en el pensamiento contemporáneo, nos permitió delimitar, como decíamos, la especificidad de un tipo de experiencia religiosa que se manifiesta en la escritura poética y se vincula al pensamiento filosófico. Fue así que indagamos la singularidad de estas experiencias poético-religiosas manifestada en la ausencia, vaciamiento o falta de lo sagrado.

Ya sea en el dios con minúsculas de Mujica, como en la mística otra de Viel, la atención de Padeletti o en la intemperie sinfin de del Barco, la experiencia poética asume lo que el pensamiento contemporáneo anuncia: que lo sagrado y lo poético acontecen en el vaciamiento, en la falta, en el despojo de nombres y des-posesión de conceptos; y así, se da materialidad a una particular experiencia poético-religiosa que responde a lo desconocido, con un lenguaje aconteciendo en el afuera de las representaciones. Porque lo que acontece en la intemperie de lo sagrado supone una imposibilidad para el lenguaje conceptual y el pensamiento discursivo, y de este modo se evidencia una singular experiencia frente a lo que hay en el mundo, a esa inmediatez que yace innominada y, frente a la cual, el lenguaje de la poesía sabe que no puede nombrar, sino sólo responder. La poesía, al responder a lo imposible, fundamentalmente está dando testimonio de eso desconocido, de esa otredad, de esa inmediatez en donde acontece la experiencia del vaciamiento de lo sagrado.

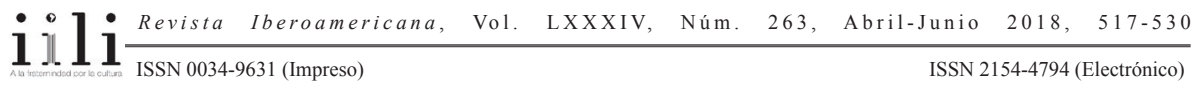


BiBLIOGRAFÍA

Barco, Oscar. El abandono de las palabras. Córdoba: CEA, UNC, 1994. J. L Ortiz. Poesía y Ética. Córdoba: Alción Editora, 1996. tú-él. Córdoba: Alción Editora, 1997 dijo. Córdoba: Alción Editora, 2000. dijo. Segunda y tercera parte. Córdoba: Alción Editora, 2001. Exceso y donación. La búsqueda del dios sin dios. Buenos Aires: Biblioteca Martín Heidegger, 2003. pobre, poco, nada. Córdoba: Alción Editora, 2005. diario. Córdoba: Alción Editora, 2007. La intemperie sin fin. Córdoba: Alción Editora, 2008.

Bataille, Georges. Sobre Nietszche. Voluntad de suerte. Madrid: Taurus, 1972. El culpable seguido de El Aleluya y fragmentos inéditos. Madrid: Taurus, 1981. La experiencia interior. Madrid: Taurus, 1981.

Blanchot, Maurice. El diálogo inconcluso. Caracas: Monte Ávila Editores, 1970. La escritura del desastre. Caracas: Monte Ávila Editores, 1990. El paso (no) más allá. Barcelona: Paidós, 1994.

Foucault, Michel. Entre filosofía y literatura. Barcelona: Paidós, 1999.

Heidegger, Martin. Sendas perdidas: Holzwege. Buenos Aires: Losada, 1960. De camino al habla. Barcelona: Odós, 1990. "El último dios". Nombres. Revista de Filosofia VI/8-9 (1996). Los himnos de Hölderlin “Germania” y "El Rin”. Buenos Aires: Biblos, 2010. Levinas, Emmanuel. De Dios que viene a la idea. Barcelona: Caparrós Editores, 1995a. Totalidad e infinito. Ensayo sobre la exterioridad. Salamanca: Sígueme, 1995b. De lo Sagrado a lo Santo. Cinco nuevas lecturas talmúdicas. Barcelona: Riopiedras, 1997. Dios, el tiempo y el Otro. Madrid: Altaya, 2000.

Marion, Jean-Luc. El ídolo y la distancia. Cinco estudios. Salamanca: Sígueme, 1999. Mujica, Hugo. La palabra inicial. La mitología del poeta en la obra de Heidegger. Madrid: Trotta, 1998.

Poéticas del vacío: Orfeo, Juan de la Cruz, Paul Celan, la utopía, el sueño y la poesía. Madrid: Trotta, 2002.

Poesía completa. 1983-2004. Buenos Aires: Seix Barral, 2005.

Milone, Gabriela. Pensamiento filosófico y experiencias religiosas en la poesía argentina contemporánea. Serie: Tesis de Posgrado. Córdoba: Editorial Filosofía y Humanidades, Universidad Nacional de Córdoba, 2014. Web.

Nancy, Jean-Luc. Des Lieux divins. France: Editions Trans-Europ-Repress, 1987. La Declosión I. La deconstrucción del cristianismo. Buenos Aires: La Cebra, 2008.

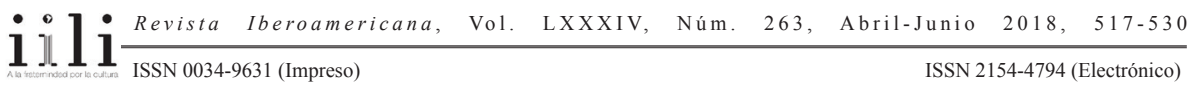


Padeletti, Hugo. La atención. Obra reunida: poemas verbales - poemas plásticos. Santa Fe: UNL, 1999.

Viel Temperley, Héctor. Obra completa. Buenos Aires: Ediciones del Dock, 2003. 